\title{
Big Five Personality Facets explaining variance in Anxiety and Depressive Symptoms in a Community Sample
}

DOI:

10.1016/j.jad.2020.05.047

\section{Document Version}

Accepted author manuscript

Link to publication record in Manchester Research Explorer

\section{Citation for published version (APA):}

Lyon, K., Juhasz, G., Brown, L. J. E., \& Elliott, R. (2020). Big Five Personality Facets explaining variance in Anxiety and Depressive Symptoms in a Community Sample. Journal of Affective Disorders, 274, 515-521. https://doi.org/10.1016/j.jad.2020.05.047

\section{Published in:}

Journal of Affective Disorders

\section{Citing this paper}

Please note that where the full-text provided on Manchester Research Explorer is the Author Accepted Manuscript or Proof version this may differ from the final Published version. If citing, it is advised that you check and use the publisher's definitive version.

\section{General rights}

Copyright and moral rights for the publications made accessible in the Research Explorer are retained by the authors and/or other copyright owners and it is a condition of accessing publications that users recognise and abide by the legal requirements associated with these rights.

\section{Takedown policy}

If you believe that this document breaches copyright please refer to the University of Manchester's Takedown Procedures [http://man.ac.uk/04Y6Bo] or contact uml.scholarlycommunications@manchester.ac.uk providing relevant details, so we can investigate your claim.

\section{OPEN ACCESS}


Big Five Personality Facets explaining variance in Anxiety and Depressive Symptoms in a

$$
\text { Community Sample }
$$

Lyon, $\mathrm{KA}^{1^{*}}$; Juhasz, $\mathrm{G}^{123}$; Brown, $\mathrm{LJE}^{4}$; Elliott, $\mathrm{R}^{1}$

This is a pre-copyedited, author-produced PDF of an article accepted for publication in The Journal of Affective Disorders following peer review. The final published version of the article Lyon et al (2020) will be made available at https://www.journals.elsevier.com/journal-ofaffective-disorders

* Address correspondence to Kieran A. Lyon, at Division of Neuroscience and Experimental Psychology, School of Biological Sciences, University of Manchester. Email:

kieran.lyon@manchester.ac.uk

1 Division of Neuroscience and Experimental Psychology, University of Manchester, M13 9PG

2 SE-NAP2 Genetic Brain Imaging Migraine Research Group, Hungarian Brain Research Program, Semmelweis University, Budapest, Hungary

3 Department of Pharmacodynamics, Faculty of Pharmacy, Semmelweis University, Budapest, Hungary

4 Division of Psychology and Mental Health, University of Manchester, M13 9PL 


\section{$\underline{\text { Abstract }}$}

Background

Personality traits are risk and protective factors in affective disorders. However, few studies have investigated the role of narrow personality facets, with existing research yielding contradictory results. Previous research has mostly focused on simple correlations. Several studies have performed separate multiple regressions within each trait, and have used nonstandard measures of personality, making it difficult to determine how individual facets make unique contributions.

Method

This study performed secondary analysis of the NewMood data set (collected 20042009), comprising 264 participants from Greater Manchester. Participants provided self-reports of all NEO-PI-R personality facets, and semi-structured questionnaires of clinical depression and anxiety. All personality facets were entered into multiple regressions to explain variance in depression and anxiety.

Results

Variance in both anxiety and depression were explained by a small number of personality facets, namely facet depression (referring to demotivation), facets positive emotion and assertiveness in extroversion, and facet competence in conscientiousness.

\section{Limitations}

This study relies on cross-sectional data and cannot determine causation. This study uses a mostly female sample, and the results were not stratified by sex due to the small sample. 


\section{Conclusion}

Previous studies suggest that broad trait neuroticism positively associates with affective disorders; this study adds that the effect of neuroticism is limited to facet depression (related to demotivation). Contrary to previous studies, no facet of agreeableness or openness explained variance in affective disorders, and facet assertiveness positively associated with affective disorder scores. These findings may help to improve treatment matching and explain the mechanisms through which affective disorders develop. 


\section{$\underline{\text { Highlights }}$}

- Neuroticism, extroversion and conscientiousness facets explained affective disorders

- Most personality facets did not significantly explain variance in affective disorders

- $\quad$ Depression was explained by 4 facets; anxiety by 5 facets 


\section{$1.1 \quad$ Introduction}

There is a long history of research into the relationship between personality and affective disorders. As early as 1902, William James wrote about a morbid-minded temperament, which contributed to the risk of developing melancholy (James, 2003). By the 1990s, personality research converged on five dimensions of personality, which are described in various five-factor models (Goldberg, 1990). Of these, the dominant model of personality became the Big Five model (Church, 1994), which posits that personality varies across five traits: neuroticism, extroversion, conscientiousness, agreeableness and openness (Costa \& McCrea, 1992). While other models of personality are still used, the widespread use of the Big Five means that results can be easily compared and integrated across the personality literature.

Big Five personality traits are derived from factor analysis, meaning each trait is a statistical common factor of various narrower personality measures (Costa \& McCrea, 1992; 1995; DeYoung et al, 2007). This means that personality can be investigated at various levels of what DeYoung calls the personality hierarchy, from broad higher-order traits, to narrow lowerorder facets (DeYoung et al, 2007). In the Neuroticism Extroversion Openness - Personality Inventory - Revised (NEO-PI-R), each personality trait comprises six facets, measured with a separate subscale, all of which correlate with each other, yet represent distinct concepts (Costa \& McCrea, 1992, 1995). For example, extroversion includes facets such as facet positive emotion, relating to positive affect in temperament (Soto \& John, 2017), and facet assertiveness, relating to dominance of others' and situations (Costa \& McCrea, 1992, 1995).

Big five personality traits are strongly related to affective disorders, with affective disorders relating to high neuroticism and low scores across the other four Big Five personality dimensions (Bienvenu et al, 2004; Eisenberg et al, 2009; Karsten et al, 2012; Kotov et al, 2010). 
For example, the amount of variance explained in depression by personality has been shown to be around 36\% (Quilty et al, 2013). There is also evidence of a reciprocal relationship between personality traits and affective disorders, with personality traits being risk factors for affective disorders, known as the vulnerability model (Ormel et al, 2013; Watson et al, 2006), and affective disorders causing changes in personality, known as the scar model (Ormel et al, 2013; Watson et al, 2006).

Personality-informed interventions at the trait level have been used for treatment matching in affective disorders. For example, individuals higher in neuroticism tend to be more responsive to pharmacotherapy compared to psychotherapy (Bagby et al, 2008, 2016). Higher extroversion also relates to greater responsiveness to interpersonal therapy (Joyce et al, 2007). Using a sample of psychiatric outpatients, Quilty et al (2013) found that lower-order personality constructs consistently explained more variance in depression than higher-order traits. Treatment-matching for affective disorders may, therefore, be improved by investigating personality facets, which are conceptually different enough to relate to different treatment approaches to affective disorders (Zinbarg et al, 2008).

Existing literature has hypothesized that personality facets may affect responsiveness to treatment. For example, individuals with lower facet positive emotion may be more responsive to Positive Psychology Interventions compared to other psychotherapies (González-Robles et al, 2019); individuals with low facet assertiveness may benefit most from assertiveness training (Zinbarg et al, 2008); and individuals low on facet competence may benefit most from behavioural activation (Martínez-Vispo et al, 2018; Kanter et al, 2010; Richards et al, 2016; Zinbarg et al, 2008). As facets have higher specificity than traits (DeYoung et al, 2007; Soto \& 
John, 2017), investigating personality facets may, therefore, improve treatment-matching for affective disorders.

Many studies rely on simple correlations (Bienvenu et al, 2004; Hayward et al, 2013;

Walton et al, 2018) or between-group comparisons (Rector et al, 2002) rather than using multiple regression to determine which combination of facets best predict affective disorders. This is important as some correlations between facets and affective disorders may be better explained by other facets, and not contribute any unique predictive value. For example, Cox et al (1999) used multiple regression, entering facets of neuroticism and anxiety sensitivity as predictors of OCD. While all six neuroticism facets significantly correlated with OCD, multiple regression reduced this to the two facets, facet anxiety and facet vulnerability, demonstrating the value of using this approach when considering facet-level predictors of all relevant traits.

Whilst some recent studies have performed multiple regressions of personality facets explaining variance in affective disorders, these analyses are often limited to individual personality domains. For example, Naragon-Gainey (2011) and Uliaszek et al (2009) only investigated facets of neuroticism, concluding that only facet depression (related to sensitivity to sadness, rather than clinical depression) positively correlated with depression. Similar multiple regressions have investigated facets of extroversion, finding that only facet positive emotion significantly negatively correlated with both depression (Naragon-Gainey et al, 2011) and psychological wellbeing (Margolis et al, 2019). Furthermore, some of these studies have derived their own personality facets from measures of both Big Five and non-Big Five personality measures in a single sample (for instance, with one study identifying four facets of extroversion (Naragon-Gainey, 2011); one identifying five facets of neuroticism (Naragon-Gainey et al, 2009); and another identifying three facets per trait (Naragon-Gainey \& Watson, 2014)). While 
these studies help to explain the structure of personality traits, such studies do not use validated measures of personality, making it different to generalize their results.

We are only aware of one study which performed multiple regressions of facets across all Big Five traits (Quilty et al, 2013). However, this study performed separate multiple regressions for facets within each personality trait. Performing separate analyses for each trait separately assumes that traits vary independently, whereas, in fact, personality traits vary across a common pattern, with individuals higher in neuroticism tending to be lower in agreeableness and conscientiousness, while individuals high in extroversion also tend to be high in openness (DeYoung et al, 2017). As Big Five traits are not entirely independent, it is possible that the effects of a facet in one personality trait may be better explained by the effect of a facet across another trait. For example, neuroticism contains the facet angry hostility, and agreeableness contains the facet trust. When analyzing personality domains separately, both facets appear to significantly explain variance in depression (Quilty et al, 2013). However, these facets have conceptual overlap, as individuals high in angry hostility may be less trustful. In fact, the factoranalysis derived personality facets used by Naragon-Gainey (2011) included mistrust as a facet of neuroticism. Future multiple regression studies should, therefore, include all personality facets as predictors in the same regression, to account for correlations and conceptual overlap between personality facets.

While previous studies use novel measures of personality facets or analyze facets from different traits separately, this study uses a single, validated measure of personality facets (all of the NEO-PI-R; Costa \& McCrea, 1985) to collectively examine the role of all personality facets on in the same multiple regression. The NEO-PI-R was considered the most appropriate measure of personality for this as it measures six facets per trait, thus providing a more focused 
level of description than other measures of the Big Five which split each trait into two aspects (DeYoung et al, 2007) or three facets (Soto \& John, 2017). While participants in the study reported symptoms relating to a range of mental illnesses, this study focuses on depression and anxiety. Based on previous research, we predict that variance in anxiety and depression will be explained by the neuroticism facet depression (Naragon-Gainey et al, 2011; Uliaszek et al, 2009), and the extroversion facet positive emotion (Naragon-Gainey, 2009; Quilty et al, 2013), and the conscientiousness facet self-discipline, the agreeableness facet trust, and the openness facet actions (Quilty et al, 2013). We also predict that the conscientiousness facet competence will explain variance in anxiety and depression, as competence conceptually overlaps with both internal locus of control and self-efficacy (DeClereck et al, 2006).

\section{$2.1 \quad$ Methodology}

\subsection{Participants}

This study uses the New Molecules in Mood Disorder (NewMood) dataset, which contains data from a range of self-report questionnaires and semi-structured interviews collected between 2004 and 2009 (Freeborough \& Kimpton, 2011; Deakin et al, 2011). This study used a general population sample. 264 participants were recruited within the Greater Manchester area of the UK through general practices and via the project website. Participants were between the ages of 18 and 60 years. Data were collected with the approval of institutional ethics committees and in accordance with the Declaration of Helsinki, and all participants gave signed informed consent (Juhasz et al, 2009). 


\section{$2.3 \quad$ Measures}

The NEO-PI-R consists of 240 items and measures six facets for each of the Big Five traits (Costa \& McCrea, 1995). Each personality facet is measured using a subscale of 8 items, and personality traits are measured by calculating total scores across these subscales. Although two of the facets of NEO-PI-R neuroticism share names with clinical disorders, namely facet depression and facet anxiety, it should be noted that these facets do not represent or conceptually relate to clinical disorders or symptoms (Costa \& McCrea, 1985; 1995). That is, facet anxiety refers to trait-like threat apprehension, relating to whether individuals perceive their environment as threatening, and how easily they worry or panic (Costa \& McCrea, 1995). Facet depression refers to both demotivation and sadness, as individuals high in facet depression are easily discouraged, and report frequently feeling guilty and low in energy (Costa \& McCrea, 1995).

The Montgomery-Åsberg Depression Rating Scale (MADRS; Montgomery \& Åsberg, 1979), which uses a semi-structured interview, was administered to assess current symptoms of depression such as sadness, anhedonia, pessimistic and suicidal thoughts, and physical symptoms involving sleep and appetite.

The Clinical Anxiety Scale (CAS; Snaith et al, 1982), which uses a semi-structured interview, was administered by a psychiatrist to assess current symptoms of anxiety disorders, including tension, ability to relax, startle response, worrying and anticipation of disaster. The interview question related to panic attacks was excluded as this pertained to panic disorder rather than anxiety disorders more broadly. Both the MADRS and CAS semi-structured interviews were carried out by trained researchers under the supervision of a psychiatrist. 


\subsection{Analysis}

Data analysis was carried out in R version 3.5.1 (supplementary material - Analysis script). Data are available upon request for researchers. Both correlational analysis and multiple regressions were carried out using the "tidyverse" and "dplyr" packages. Correlations between personality facets were conducted to test for multicollinearity. This was confirmed by calculating variance inflation factors (VIFs) of personality facets using the "car" package with a threshold of VIF>10 (Dormann et al, 2013). All 30 NEO-PI-R personality facets were simultaneously entered into a multiple regression model to determine which combination of facets best explained variance in both depression and anxiety. A post-hoc power analysis in G*power (version 3.1) found that both multiple regressions achieved $>99 \%$ statistical power.

Several facets correlated with each other over the multicollinearity threshold of $r=0.7$ (supplementary tables 3 and 4). High multicollinearity can lead to inflated variance in hierarchical regression (Dormann et al, 2013). Therefore, variance inflation factor (VIF) was calculated between all predictors. 30 VIF calculations were performed, one for each NEO-PI-R facet as an outcome variable. Facet depression consistently had the highest VIF, between 4.43 (when facet anxiety was the outcome variable), and 5.57 (when facet assertiveness was the outcome variable; and when facet dutifulness was the outcome variable). As all VIF statistics were below 10, variance would not be inflated, meaning multiple regression could be carried out using ordinary least squares regression (Dormann et al, 2013).

This paper also investigates the possibility of suppressor effects, in which the predictive validity of variables is inflated (Conger, 1974). Suppressor effects result from high correlations between variables, including variables sharing statistical common factors (Beckstead, 2012; Conger, 1974), such as multiple personality facets mapping onto personality a trait. Zero-order 
correlations between predictors and outcome variables were therefore investigated to determine whether significant regression coefficients could be explained by suppressor effects (Beckstead, 2012).

\section{$3.1 \quad \underline{\text { Results }}$}

\subsection{Participant characteristics}

The sample comprised 264 participants, with 185 females and 79 males. The average age of participants was 33.56 years $(\mathrm{SD}=11.00$ years $)$. The vast majority of participants were white, making up $95.45 \%$ of the sample. A quarter of the sample were married, and $20.46 \%$ of the sample reported one or more children under the age of 16 living with them. The vast majority of the sample (98.48\%) had GCSE's or O-level secondary school qualifications, and $53.41 \%$ of the sample reporting have a degree. $45.07 \%$ of the sample reported working full-time; $13.26 \%$ reported working part-time; $29.54 \%$ were university students, and $9.85 \%$ of the sample reported being unemployed.

All participants completed a background questionnaire, which included yes/no questions about whether they had a history of various mental illnesses. Analysis of the NewMood background questionnaire found that over half of the sample reported a history of depression, while a quarter of the sample reported a history of an anxiety disorder. A history of an eating disorder was reported by $8.71 \%$, and a history of drug or alcohol problems was reported by $8.71 \%$ of the sample (table 1). Means and standard deviations MADRS depression symptoms, CAS anxiety symptoms and NEO-PI-R personality facets are provided in supplementary table 1. 
Table 1. Rates of psychiatric history by disorder and sex

\begin{tabular}{|l|l|l|l|}
\hline Psychiatric history & Total sample (\%) & Males (\%) & Females (\%) \\
\hline Depression & 58.33 & 45.57 & 63.78 \\
\hline Suicide attempt/self-harm & 18.56 & 15.19 & 20 \\
\hline Manic episode/bipolar & 1.52 & 2.53 & 1.08 \\
\hline Anxiety/panic/phobia & 25.00 & 20.25 & 27.03 \\
\hline OCD & 1.89 & 0.00 & 2.70 \\
\hline Eating disorder & 8.71 & 1.27 & 11.89 \\
\hline Drug or alcohol problem & 3.41 & 6.33 & 2.16 \\
\hline Other & 1.14 & 1.27 & 1.08 \\
\hline
\end{tabular}

3.3 Multiple regression of personality facets explaining variance in depression

When all 30 NEO-PI-R facets were entered into a single model, variance in MADRS was significantly explained by the facets depression $(b=0.5, t=4.45, \mathrm{p}<0.05)$, facet assertiveness $(b=0.32, t=2.85, p<0.05)$, facet positive emotion $(b=-0.40, t=-3.22, p<0.05)$ and facet competence $(b=-0.39, t=0.15, p<0.05$; table 2; figure 1). Facet depression and facet assertiveness were risk factors, while facet positive emotion and facet competence were protective.

Analysis of variance found that the model including facet depression, facet assertiveness, facet positive emotion and facet competence did not significantly differ from a model including all 30 NEO-PI-R facets as predictors of MADRS $(\operatorname{Pr}(>\mathrm{F})=0.11)$.

3.4 Multiple regression of personality facets explaining variance in anxiety

When all 30 NEO-PI-R facets were entered into a single model, variance in CAS was significantly explained by facet depression $(b=0.18, t=3.33, p=0.001)$, facet gregariousness $(b=-$ $0.11, \mathrm{t}=-1.99, \mathrm{p}<0.05)$, facet assertiveness $(\mathrm{b}=0.17, \mathrm{t}=3.14, \mathrm{p}=0.002)$, facet positive emotion $(\mathrm{b}=-$ $0.14, \mathrm{t}=-2.38, \mathrm{p}<0.05)$ and facet competence $(\mathrm{b}=-0.25, \mathrm{t}=-3.50, \mathrm{p}<0.001$; table 3 ; figure 2$)$. Facet depression and facet assertiveness were risk factors, while facet gregariousness, facet positive emotion and facet competence were protective. 
Analysis of variance found that the model including facet depression, facet gregariousness, facet assertiveness, facet positive emotion and facet competence did not significantly differ from a model including all 30 NEO-PI-R facets as predictors of CAS $(\operatorname{Pr}(>\mathrm{F})$ $=0.17)$.

Figure 1. Personality facets explaining variance in depression.

NEO-PI-R facets explaining variance in MADRS scores. Facets in red positively correlated with MADRS scores. Facets in blue negatively correlated with MADRS scores.

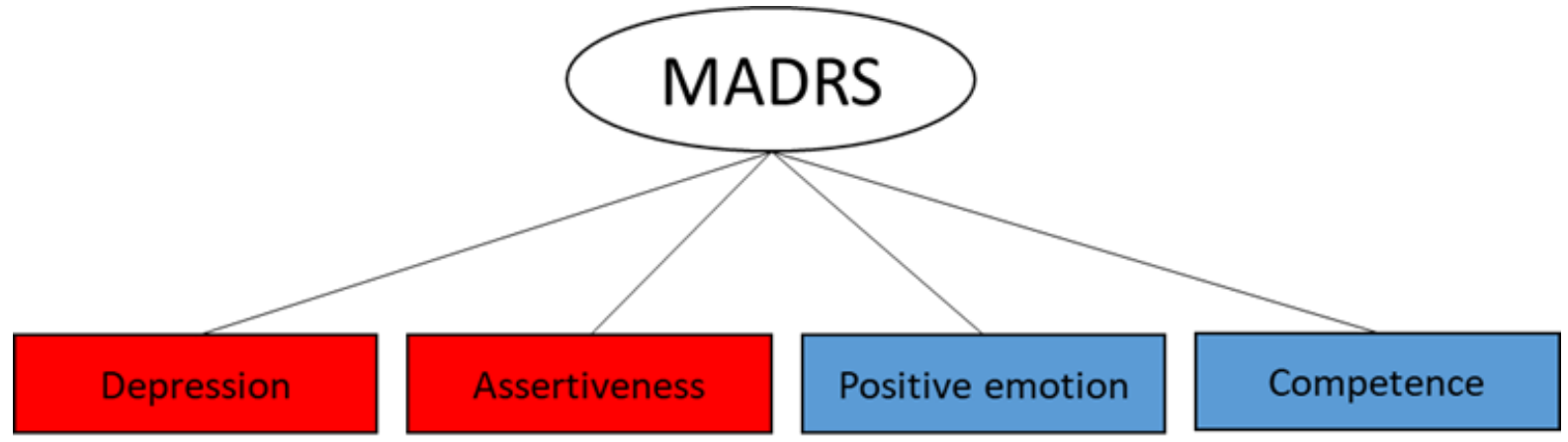

Figure 2. Personality facets explaining variance in anxiety.

NEO-PI-R facets explaining variance in CAS scores. Facets in red positively correlated with CAS scores. Facets in blue negatively correlated with CAS scores.

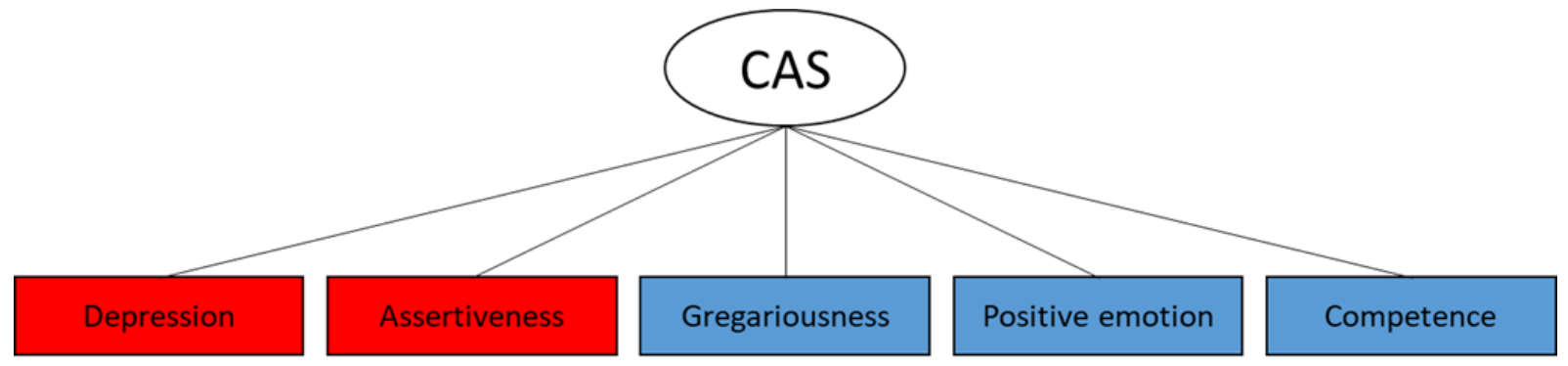


Table 2. Personality facets explaining variance in depression

All 30 NEO-PI-R facets explaining variance in MADRS scores. All figures are given to 2 decimal places. $*$ significant at $\mathrm{p}<0.05$. $* *$ significant at $\mathrm{p}<0.01$. $* * *$ significant at $\mathrm{p}<0.001$

\begin{tabular}{|c|c|c|c|c|}
\hline Trait & Facet & Estimate & Std. error & $\mathrm{t}$ value \\
\hline \multirow[t]{6}{*}{ Neuroticism } & Anxiety & -0.17 & 0.11 & -1.58 \\
\hline & Angry hostility & 0.02 & 0.12 & 0.18 \\
\hline & Depression & 0.50 & 0.11 & $4.45 * * *$ \\
\hline & Self-consciousness & -0.10 & 0.12 & -0.89 \\
\hline & Impulsivity & -0.15 & 0.11 & -1.39 \\
\hline & Vulnerability & 0.08 & 0.14 & 0.57 \\
\hline \multirow[t]{6}{*}{ Extroversion } & Warmth & -0.05 & 0.17 & -0.32 \\
\hline & Gregariousness & -0.20 & 0.11 & -1.76 \\
\hline & Assertiveness & 0.32 & 0.11 & $2.85 * * *$ \\
\hline & Activity & -0.09 & 0.13 & -0.67 \\
\hline & Excitement-seeking & -0.10 & 0.11 & -0.91 \\
\hline & Positive emotion & -0.40 & 0.12 & $-3.22 * * *$ \\
\hline \multirow[t]{6}{*}{ Conscientiousness } & Competence & -0.39 & 0.15 & $-2.64 * * *$ \\
\hline & Order & -0.03 & 0.10 & -0.34 \\
\hline & Dutifulness & -0.22 & 0.13 & -1.65 \\
\hline & Achievement striving & 0.08 & 0.12 & 0.67 \\
\hline & Self-discipline & 0.10 & 0.12 & 0.87 \\
\hline & Deliberation & -0.11 & 0.11 & -0.97 \\
\hline \multirow{6}{*}{ Agreeableness } & Trust & -0.12 & 0.11 & -1.02 \\
\hline & Straightforwardness & 0.10 & 0.12 & 0.87 \\
\hline & Altruism & 0.26 & 0.16 & 1.57 \\
\hline & Compliance & 0.04 & 0.10 & 1.57 \\
\hline & Modesty & -0.12 & 0.11 & -1.12 \\
\hline & Tendermindedness & 0.06 & 0.13 & 0.45 \\
\hline \multirow[t]{6}{*}{ Openness } & Fantasy & 0.04 & 0.10 & 0.45 \\
\hline & Aesthetics & 0.15 & 0.09 & 1.57 \\
\hline & Feelings & 0.10 & 0.14 & 0.76 \\
\hline & Actions & -0.22 & 0.12 & -1.76 \\
\hline & Ideas & -0.01 & 0.10 & -0.13 \\
\hline & Values & -0.07 & 0.15 & -0.45 \\
\hline
\end{tabular}


Table 3. Personality facets explaining variance in anxiety

All 30 NEO-PI-R facets explaining variance in CAS scores. All figures are given to 2 decimal places. * significant at $\mathrm{p}<0.05 . * *$ significant at $\mathrm{p}<0.01 . * * *$ significant at $\mathrm{p}<0.001$

\begin{tabular}{|c|c|c|c|c|}
\hline Trait & Facet & Estimate & Std. error & $\mathrm{t}$ value \\
\hline \multirow[t]{6}{*}{ Neuroticism } & Anxiety & 0.02 & 0.05 & 0.47 \\
\hline & Angry hostility & -0.00 & 0.06 & -0.01 \\
\hline & Depression & 0.18 & 0.05 & $3.33 * * *$ \\
\hline & Self-consciousness & -0.07 & 0.06 & -1.22 \\
\hline & Impulsivity & -0.04 & 0.05 & -0.74 \\
\hline & Vulnerability & 0.05 & 0.07 & 0.71 \\
\hline \multirow{6}{*}{ Extroversion } & Warmth & -0.05 & 0.08 & -0.59 \\
\hline & Gregariousness & -0.11 & 0.05 & $-1.99 *$ \\
\hline & Assertiveness & 0.17 & 0.05 & $3.14 * * *$ \\
\hline & Activity & -0.00 & 0.06 & -0.02 \\
\hline & Excitement-seeking & -0.08 & 0.05 & -1.51 \\
\hline & Positive emotion & -0.14 & 0.06 & $-2.38^{*}$ \\
\hline \multirow[t]{6}{*}{ Conscientiousness } & Competence & -0.25 & 0.07 & $-3.50 * * *$ \\
\hline & Order & 0.05 & 0.05 & 0.95 \\
\hline & Dutifulness & -0.04 & 0.06 & -0.64 \\
\hline & Achievement striving & 0.10 & 0.06 & 1.78 \\
\hline & Self-discipline & 0.01 & 0.06 & 0.22 \\
\hline & Deliberation & -0.06 & 0.05 & -1.15 \\
\hline \multirow[t]{6}{*}{ Agreeableness } & Trust & -0.07 & 0.05 & -1.22 \\
\hline & Straightforwardness & 0.02 & 0.06 & 0.41 \\
\hline & Compliance & 0.03 & 0.07 & 0.82 \\
\hline & Altruism & 0.13 & 0.08 & 1.65 \\
\hline & Modesty & -0.06 & 0.05 & -1.12 \\
\hline & Tendermindedness & 0.05 & 0.06 & 0.84 \\
\hline \multirow[t]{6}{*}{ Openness } & Fantasy & 0.04 & 0.05 & 0.82 \\
\hline & Aesthetics & 0.07 & 0.05 & 1.58 \\
\hline & Feelings & -0.01 & 0.07 & -0.16 \\
\hline & Actions & -0.07 & 0.06 & -1.19 \\
\hline & Ideas & -0.04 & 0.05 & -0.89 \\
\hline & Values & -0.04 & 0.07 & -0.62 \\
\hline
\end{tabular}




\subsection{Investigation of suppressor effects}

In his foundational paper on suppressor effects, Conger (1974) identified three types of suppressor situations: traditional suppression, in which a non-significant correlation between a predictor and an outcome variable results in a significant regression coefficient controlling for other variables; reciprocal suppression, when two predictor variables significantly negatively correlate with each other, but both significantly correlate with the outcome variable; and negative suppression, also called cross-over suppression, in which a weak positive correlation results in negative regression coefficient (Beckstead, 2012; Paulhus et al, 2004; Watson et al, 2013). Zeroorder correlations between all personality facets, and between personality facets and affective disorder scores, were investigated to determine whether significant effects were explained by statistical suppression (Beckstead, 2012).

All variables significantly explaining variance in MADRS and CAS scores in the multiple regression had at least moderate Pearson correlations with outcome variables. These ranged from $\mathrm{r}=-0.32, \mathrm{p}<0.001$ (facet assertiveness and CAS) to $\mathrm{r}=0.63, \mathrm{p}<0.001$ (facet depression and MADRS; supplementary table 2) and suggest that results are unlikely to be explained by traditional suppression. Reciprocal suppression is also unlikely, as no significant predictors negatively correlated with each other, while both positively correlating with affective disorder scores (supplementary tables 2, 3 and 4). Facet assertiveness negatively correlated with both MADRS $(\mathrm{r}=-0.35, \mathrm{p}<0.001)$ and CAS $(\mathrm{r}=-0.32, \mathrm{p}<0.001)$. However, facet assertiveness positively regressed onto both MADRS and CAS in the multiple regression analyses. This reversal suggests a negative, or cross-over, suppression situation. 


\subsection{Discussion}

The aim of this study was to investigate which personality facets uniquely explain variance in affective disorders. Previous research has focused on simple correlations (Bagby et al, 1995; Hayward et al, 2013; Newby et al, 2017) or performed separate multiple regression analyses for each personality domain (Quilty et al, 2013), making it difficult to determine the unique contributions of individual personality facets. Several studies using multiple regression have derived personality facets from factor analysis of both Big Five and non-Big Five measures, rather than validated personality measures, making it difficult to generalize results (NaragonGainey et al, 2009; Naragon-Gainey, 2011; Naragon-Gainey \& Watson, 2014). This is the first study we are aware of to enter all NEO-PI-R facets into a single multiple regression to explain variance in both anxiety and depression. The findings of this study adds to the existing literature by showing that the previously-observed effects of neuroticism were limited to facet depression (referring to demotivation); that variance in anxiety and depression were also explained by facet positive emotion and facet assertiveness in extroversion, and facet competence in conscientiousness; and that the extroversion facet gregariousness was included in the best fit model of anxiety, but not depression. Another novel finding of this work is that no facets of agreeableness or openness uniquely explained variance in anxiety or depression.

A novel finding of this study is that, of all facets of neuroticism, only facet depression uniquely explained variance in affective disorders. This facet does not refer to clinical depression, but instead refers to both demotivation and sadness, as individuals high in facet depression report being easily discouraged and often feeling hopeless (Costa \& McCrea, 1992; 1995). This conflicts with correlational studies suggesting that all six NEO-PI-R neuroticism facets correlate with anxiety disorders, and that broad trait neuroticism positively associates with 
affective disorders (Hayward et al, 2013; Newby et al, 2017; Quilty et al, 2013), and suggests that these previously-observed correlations between neuroticism facets and affective disorder scores are likely best explained by the effect of facet depression. As facet depression involves motivation (Costa \& McCrea, 1985, 1995), this suggests that neuroticism contributes to affective disorders not through high sensitivity to negative affect, but also through lower persistence of positive affect. This suggests that individuals low in facet depression may therefore benefit from psychological therapies focusing on developing persistent motivation, such as Motivational Interviewing (Rubak et al, 2005) or Behavioural Activation (Kanter et al, 2010).

Two of the personality facets contributing to affective disorders conceptually relate to motivation: facet depression (which includes demotivation); and facet positive emotion (sensitivity to positive affect). Positive affect has been conceptualized as approach motivation, maintained by progress toward goals (Carver \& Schieier, 2013; Wilt et al, 2017). Furthermore, maladaptive goals contribute to affect disorders, with anxiety disorders being associated with unrealistic avoidance goals away from threats, and depressive disorder associated with unrealistic approach goals toward challenges (Bandura, 1997, pp. 153-156; Eccles et al, 2014; Johnson et al, 2010). Taken together, these findings therefore suggest that individuals high in facet depression, and low in facet positive emotion, may benefit from treatments focusing on adaptive goal setting, such as Behavioural Activation (Kanter et al, 2010), as well as treatments focusing on motivation and positive affect, such as Motivational Interviewing (Rubak et al, 2005) and Positive Psychology Interventions (Chaves et al, 2017).

Another novel finding of this study is, when considered alongside other facets, there was a positive associated between facet assertiveness and anxiety and depression symptoms. This contrasts with the results of simple, pairwise correlations (both in the current paper and in 
previous studies (Bagby et al, 1995; Quilty et al, 2013), which have shown these associations to be negative. This is an example of negative, or cross-over, suppression, in which the relationship between a predictor variable and the outcome variable reverse when controlling for additional predictors (Beckstead, 2012; Conger, 1974). While suppression effects are often dismissed as statistical artefacts, several suppression effects in personality research have been replicated (Paulhus et al, 2004; Watson et al, 2013), suggesting that they can be theoretically meaningful, and highlight the differential impact of facets within a common factor (Watson et al, 2013). One possible explanation is that the effect of facet assertiveness may have been masked by that of facet positive emotion. As facet assertiveness conceptually relates to forcefulness and social dominance (Costa \& McCrea, 1995a, 1995b), it is possible that these characteristics reduce social support. The effect of facet assertiveness ay be moderated by social support associated with facet positive emotion.

In line with previous research, personality facets explaining depression and anxiety greatly overlapped: all facets explaining variance in depression also explained variance in anxiety. These common personality mechanisms help to explain the high comorbidity of anxiety and depression (Hopwood et al, 2018; Kotov et al, 2017). Nevertheless, the extroversion facet gregariousness explained variance in anxiety but not depression. Individuals with clinical anxiety often perceive their environment in terms of threats with which they are unable to cope (Eccles et al 2014; Johnson et al, 2010). Individuals higher in facet gregariousness may have more social support to cope with these perceived threats, which may reduce anxiety severity.

Another primary finding is that variance in affective disorders symptoms was explained by the conscientiousness facet competence, but not by the conscientiousness facet self-discipline. Previous studies have consistently suggested that both facet competence and facet self-discipline 
negatively correlate affective disorders (Cox et al, 2000; Jourdy \& Petot, 2017; Naragon-Gainey et al, 2017). Facet competence, also called generalized self-efficacy (Costa \& McCrea, 1992) refers to an individuals' belief in the ability to solve problems. Facet competence may protect from affective disorders via problem-focused coping (Mirnics et al, 2013) and protecting from maladaptive beliefs such as hopelessness (Abramson et al, 1978; Anderson \& McLean, 1997; Schurer et al, 2017). Previous researchers have suggested that facet self-discipline improves emotion regulation which protects from affective disorders (Eisenberg et al, 2014). However, this study adds that the effect of facet self-discipline is explained by facet competence. This may imply that self-discipline contributes to affective disorders, not via relation of negative emotions, but through the development of skills to respond to stressors.

One surprising result from this study is that facet anxiety does not uniquely explain variance in affective disorder. Facet anxiety does not refer to clinical anxiety, but to trait-like threat apprehension (Costa \& McCrea, 1992; 1995). Entering all facets of neuroticism in a multiple regression, Quilty et al (2013) found that variance in depression was significantly explained by both facet depression and facet anxiety. However, the effect of anxiety becomes non-significant controlling for other facets of other traits. One possible explanation is that the effect of anxiety is masked by the effect of competence, suggesting that an individuals' level of facet competence determines whether stressors are appraised as threats or challenges (Bandura, 1994; Folkman, 1984). Therefore, individuals low in facet competence may be more likely to perceive environments as threatening and have higher facet anxiety, and thus benefit more from treatments focusing on developing skills and coping strategies, such as Behavioural Activation (Kanter et al, 2010), compared to other psychotherapies. 
Another novel result is that no facet of agreeableness or openness uniquely explained variance in affective disorders. Previous research has consistently found that facet trust in agreeableness, and facet actions in openness, significantly negatively associates with affective disorders. However, such studies rely on simple correlations (Jourdy \& Petot, 2017; Kaplan et al, 2015; Wolfestein \& Trull, 1997) or perform separate regression analyses for each personality trait (Quilty et al, 2013). The current study suggests that these effects are better explained by facets of neuroticism, conscientiousness and extroversion, and implies that treatment-matching for affective disorders should primarily focus on neuroticism, extroversion and conscientiousness.

As the multiple regressions included many predictors, some of which are highly correlated, results may be affected by multicollinearity (Dormann et al, 2013) or suppressor effects (Beckstead, 2012; Conger, 1974). No personality facets had a VIF of over 10, the common multicollinearity threshold (Dormann et al, 2013), meaning it is unlikely that regression coefficients were artificially inflated. Nevertheless, many facets had statistical common factors, increasing the likelihood of suppressor effects (Beckstead, 2012; Conger, 1974). Investigations of zero-order correlations between personality facets, and between personality facets and affective disorder scores, lead us to conclude that the effects of facet assertiveness on affective disorders were negative, or cross-over, suppression effects. As discussed above, this suppression effect is not necessarily a statistical artefact but instead may be a meaningful result (Paulhus et al, 2004; Watson et al, 2013), explaining the complex role of assertiveness in affective disorders.

This study is not without limitations. Firstly, using a cross-sectional design, this study is unable to test models of causation. Secondly, by measuring broad clinical anxiety with CAS, the current study is also unable to distinguish between anxiety disorders. Furthermore, participants 
reported mental illnesses other than affective disorders, meaning the results may be affected by comorbidity. However, comorbidity is common in psychopathology (Hopwood et al, 2018; Kotov et al, 2017) therefore a sample with comorbidity may be more representative than pure cases of affective disorders. Thirdly, the current study also does not investigate the relationships between personality facets and specific symptoms; while this is an interesting area of research, it is beyond the scope of this study and is a potential area for future research. Fourthly, the current study has a relatively small and mostly female sample ( $\mathrm{N}=264,70.08 \%$ female), meaning this study is not able to determine whether results differ by sex. The effect of sex on personality facets explaining variance in affective disorders is another possible area for future research. Fifthly, the large number of predictor variables per analysis may have led to unstable results. Although both multiple regressions achieved $>99 \%$ statistical power, further replication of these findings in additional datasets is now needed.

\section{$5.1 \quad$ Conclusion}

When accounting for all facets, facets positive emotion and competence negatively associated with affective disorder scores; facets depression (relating to demotivation) and assertiveness positively associated with affective disorder scores. Facet gregariousness also negatively associated with anxiety but not depression scores. The results suggest that the effect of neuroticism is largely driven by facet depression (referring to demotivation). The significant effects of facets depression and positive emotion suggest that several personality constructs contribute to affective disorders via incentive reward sensitivity, rather than negative affect as previous suggested (Ormel et al, 2013; Watson et al, 2006). Contrary to previous research, this study also suggests that facet assertiveness positively associates with affective disorders, when 
controlling for other personality facets; and that no facet of assertiveness or openness significantly contribute to affective disorders. Treatment-matching for affective disorders may be improved by focusing on these narrow facets.

\section{1 $\quad$ Acknowledgement and author contributions}

All authors were involved in study conceptualization and report writing. Rebecca Elliott and Gabriella Juhasz were involved in data collection. Kieran Lyon conducted all data analyses. We would like to thank Nóra Eszlári for providing feedback on all data analyses.

The NewMood study was supported by the Sixth Framework Program of the European Union (LSHM-CT-2004-503474). Gabriella Juhasz was supported by the Hungarian Brain Research Program (KTIA_NAP_13-2-2015-0001, 2017-1.2.1-NKP-2017-00002) and the Manchester Academic Health Sciences Centre, Manchester, United Kingdom. The authors report no conflict of interest.

6.2 Role of the Funding source

This study was carried out as part of a self-funded Ph.D., administered by the UK's Student Loans Company. No funding organization was involved in the conceptualizing, planning, analysis or writing of this study.

\section{$\underline{\text { Conflict of interest }}$}

The authors report no conflict of interest. 
References

Abramson, L. Y., Seligman, M. E., \& Teasdale, J. D. (1978). Learned helplessness in humans: Critique and reformulation. Journal of abnormal psychology, 87(1), 49

Anderson, K. W., \& Mclean, P. D. (1997). Conscientiousness in depression: Tendencies, predictive utility, and longitudinal stability. Cognitive Therapy and Research, 21(2), 223238

Bagby, R. M., Joffe, R. T., Parker, J. D., Kalemba, V., \& Harkness, K. L. (1995). Major depression and the five-factor model of personality. Journal of Personality Disorders, 9(3), 224-234

Bagby, R. M., Quilty, L. C., Segal, Z. V., McBride, C. C., Kennedy, S. H., \& Costa Jr, P. T. (2008). Personality and differential treatment response in major depression: a randomized controlled trial comparing cognitive-behavioural therapy and pharmacotherapy. The Canadian Journal of Psychiatry, 53(6), 361-370

Bagby, R. M., Gralnick, T. M., Al-Dajani, N., \& Uliaszek, A. A. (2016). The role of the fivefactor model in personality assessment and treatment planning. Clinical Psychology: Science and Practice, 23(4), 365-381

Bandura, A. (1994). Self-efficacy. In. VS Ramachaudran. Encyclopedia of human behavior, 4(4), 71-81

Bandura, A. (1997). Self-efficacy: The exercise of control. H. Freeman. New York, NY

Beckstead, J. W. (2012). Isolating and examining sources of suppression and multicollinearity in 
multiple linear regression. Multivariate Behavioral Research, 47(2), 224-246

Bienvenu, O. J., Samuels, J. F., Costa, P. T., Reti, I. M., Eaton, W. W., \& Nestadt, G. (2004). Anxiety and depressive disorders and the five-factor model of personality: A higher-and lower-order personality trait investigation in a community sample. Depression and anxiety, 20(2), 92-97

Carver, C. S., \& Scheier, M. F. (2013). Goals and emotion. Guilford handbook of cognition and emotion, 176-194

Chaves, C., Lopez-Gomez, I., Hervas, G., \& Vazquez, C. (2017). A comparative study on the efficacy of a positive psychology intervention and a cognitive behavioral therapy for clinical depression. Cognitive Therapy and Research, 41(3), 417-433

Church, A. T. (1994). Relating the Tellegen and five-factor models of personality structure. Journal of Personality and Social Psychology, 67(5), 898

Conger, A. J. (1974). A revised definition for suppressor variables: A guide to their identification and interpretation. Educational and psychological measurement, 34(1), 35-46

Costa, P. T., \& McCrae, R. R. (1985). The NEO personality inventory

Costa, P. T., \& McCrae, R. R. (1992). Normal personality assessment in clinical practice: The NEO Personality Inventory. Psychological assessment, 4(1), 5

Costa Jr, P. T., \& McCrae, R. R. (1995). Domains and facets: Hierarchical personality assessment using the Revised NEO Personality Inventory. Journal of personality assessment, 64(1), 21-50

Cox, B. J., Borger, S. C., Taylor, S., Fuentes, K., \& Ross, L. M. (1999). Anxiety sensitivity and 
the five-factor model of personality. Behaviour Research and Therapy, 37(7), 633-641

Cox, B. J., Borger, S. C., Asmundson, G. J., \& Taylor, S. (2000). Dimensions of hypochondriasis and the five-factor model of personality. Personality and individual differences, 29(1), 99-108

Deakin, J. F., Harro, J., \& Anderson, I. M. (2011). NewMood: a productive European model of collaboration for translational research in depression. [Editorial Introductory Research Support, Non-U.S. Gov't]. Eur Neuropsychopharmacol, 21(1), 1-2. doi: 10.1016/j.euroneuro.2010.11.008.

DeYoung, C. G., Quilty, L. C., \& Peterson, J. B. (2007). Between facets and domains: 10 aspects of the Big Five. Journal of personality and social psychology, 93(5), 880

Dormann, C. F., Elith, J., Bacher, S., Buchmann, C., Carl, G., Carré, G., ... \& Münkemüller, T. (2013). Collinearity: a review of methods to deal with it and a simulation study evaluating their performance. Ecography, 36(1), 27-46

DeClerck, C. H., Boone, C., \& De Brabander, B. (2006). On feeling in control: a biological theory for individual differences in control perception. Brain and cognition, 62(2), 143176

Eccles, L. (2014). Approach-and avoidance-goal cognitions in depression and anxiety (Doctoral dissertation, University of Liverpool)

Eisenberg, N., Valiente, C., Spinrad, T. L., Cumberland, A., Liew, J., Reiser, M., ... \& Losoya, S. H. (2009). Longitudinal relations of children's effortful control, impulsivity, and negative emotionality to their externalizing, internalizing, and co-occurring behavior problems. Developmental psychology, 45(4), 988 
Eisenberg, N., Duckworth, A. L., Spinrad, T. L., \& Valiente, C. (2014). Conscientiousness: Origins in childhood? Developmental Psychology, 50(5), 1331

Fossati, A., Borroni, S., Marchione, D., \& Maffei, C. (2011). The big five inventory (BFI). European Journal of Psychological Assessment

Freeborough, A., \& Kimpton, J. (2011). Discovering new genetic and psychosocial pathways in Major Depressive Disorder: the NewMood project. Psychiatr Danub, 23(Suppl 1), S138S141

Fritz, J., Fried, E. I., Goodyer, I. M., Wilkinson, P. O., \& Van Harmelen, A. L. (2018). A Network Model of Resilience Factors for Adolescents with and without Exposure to Childhood Adversity

Goldberg, L. R. (1990). An alternative "description of personality": The Big-Five factor structure. Journal of Personality and Social Psychology, 59(6), 1216-1229

González-Robles, A., García-Palacios, A., Baños, R., Quero, S., \& Botella, C. (2019). Upregulating Positive Affectivity in the Transdiagnostic Treatment of Emotional Disorders: A Randomized Pilot Study. Behavior modification, 43(1), 26-55

Hayward, R. D., Taylor, W. D., Smoski, M. J., Steffens, D. C., \& Payne, M. E. (2013). Association of five-factor model personality domains and facets with presence, onset, and treatment outcomes of major depression in older adults. The American Journal of Geriatric Psychiatry, 21(1), 88-96

Hopwood, C., Bagby, R. M., Gralnick, T. M., Ro, E., Ruggero, C., Mullins-Sweatt, S., ... \& 
Patrick, C. J. (2018). Integrating psychotherapy with the Hierarchical Taxonomy of Psychopathology (HiTOP)

Johnson, S. L., Carver, C. S., \& Fulford, D. (2010). Goal dysregulation in the affective disorders. Emotion regulation and psychopathology: A transdiagnostic approach to etiology and treatment, 204-228

James, W. (2003). The varieties of religious experience: A study in human nature. Lectures 6-7, “The Sick Soul," pp. 99-127. Routledge

Jourdy (2013). Can we provide the evolution of a non psychotic depression from the personality traits and the initial clinical pictures? (prospective longitudinal study of 43 patients over twelve months). (Unpublished doctoral thesis). Paris Nanterre University, Paris, France

Jourdy, R., \& Petot, J. M. (2017). Relationships between personality traits and depression in the light of the "Big Five" and their different facets. L'Évolution Psychiatrique, 82(4), e27e37

Joyce, P. R., McKenzie, J. M., Carter, J. D., Rae, A. M., Luty, S. E., Frampton, C. M., \& Mulder, R. T. (2007). Temperament, character and personality disorders as predictors of response to interpersonal psychotherapy and cognitive-behavioural therapy for depression. The British Journal of Psychiatry, 190(6), 503-508

Juhasz, G., Chase, D., Pegg, E., Downey, D., Toth, Z. G., Stones, K., ... \& Anderson, I. M. (2009). CNR1 gene is associated with high neuroticism and low agreeableness and interacts with recent negative life events to predict current depressive symptoms. Neuropsychopharmacology, 34(8), 2009

Kanter, J. W., Manos, R. C., Bowe, W. M., Baruch, D. E., Busch, A. M., \& Rusch, L. C. (2010). 
What is behavioral activation?: A review of the empirical literature. Clinical psychology review, 30(6), 608-62

Karsten, J., Penninx, B. W., Riese, H., Ormel, J., Nolen, W. A., \& Hartman, C. A. (2012). The state effect of depressive and anxiety disorders on big five personality traits. Journal of psychiatric research, 46(5), 644-650

Kotov, R., Gamez, W., Schmidt, F., \& Watson, D. (2010). Linking "big” personality traits to anxiety, depressive, and substance use disorders: a meta-analysis. Psychological bulletin, 136(5), 768

Kotov, R., Krueger, R. F., Watson, D., Achenbach, T. M., Althoff, R. R., Bagby, R. M., ... \& Eaton, N. R. (2017). The Hierarchical Taxonomy of Psychopathology (HiTOP): A dimensional alternative to traditional nosologies. Journal of abnormal psychology, 126(4), 454

Margolis, S., Stapley, A. L., \& Lyubomirsky, S. (2019). The Association Between Extraversion and Well-Being is Limited to One Facet. Journal of personality

Martínez-Vispo, C., Martínez, Ú., López-Durán, A., del Río, E. F., \& Becoña, E. (2018). Effects of behavioural activation on substance use and depression: a systematic review. Substance abuse treatment, prevention, and policy, 13(1), 36

Mirnics, Z., Heincz, O., Bagdy, G., Surányi, Z., Gonda, X., Benko, A., ... \& Juhasz, G. (2013). The relationship between the big five personality dimensions and acute psychopathology: mediating and moderating effects of coping strategies. Psychiatria Danubina, 25(4), 0388

Montgomery, S. A., \& Åsberg, M. A. R. I. E. (1979). A new depression scale designed to be 
sensitive to change. The British journal of psychiatry, 134(4), 382-389

Naragon-Gainey, K., Watson, D., \& Markon, K. E. (2009). Differential relations of depression and social anxiety symptoms to the facets of extraversion/positive emotionality. Journal of abnormal psychology, 118(2), 299

Naragon-Gainey, K. E. (2011). A lower order structural examination of the neuroticism/negative emotionality domain: Relations with internalizing symptoms and selected clinical traits

Naragon-Gainey, K., \& Watson, D. (2014). Consensually defined facets of personality as prospective predictors of change in depression symptoms. Assessment, 21(4), 387-403

Ormel, J., Jeronimus, B. F., Kotov, R., Riese, H., Bos, E. H., Hankin, B., ... \& Oldehinkel, A. J. (2013). Neuroticism and common mental disorders: meaning and utility of a complex relationship. Clinical psychology review, 33(5), 686-697

Osma López, J. J., Barrada, J. R., García-Palacios, A., \& Botella, C. (2016). Influence of vulnerability factors in panic disorder severity

Patrick, C. J., Curtin, J. J., \& Tellegen, A. (2002). Development and validation of a brief form of the Multidimensional Personality Questionnaire. Psychological assessment, 14(2), 150

Paulhus, D. L., Robins, R. W., Trzesniewski, K. H., \& Tracy, J. L. (2004). Two replicable suppressor situations in personality research. Multivariate Behavioral Research, 39(2), $303-328$

Quilty, L. C., Pelletier, M., DeYoung, C. G., \& Bagby, R. M. (2013). Hierarchical personality traits and the distinction between unipolar and bipolar disorders. Journal of affective disorders, 147(1-3), 247-254 
Rector, N. A., Hood, K., Richter, M. A., \& Bagby, R. M. (2002). Obsessive-compulsive disorder and the five-factor model of personality: Distinction and overlap with major depressive disorder. Behaviour Research and Therapy, 40(10), 1205-1219

Richards, D. A., Ekers, D., McMillan, D., Taylor, R. S., Byford, S., Warren, F. C., ... \& O'Mahen, H. (2016). Cost and Outcome of Behavioural Activation versus Cognitive Behavioural Therapy for Depression (COBRA): a randomised, controlled, non-inferiority trial. The Lancet, 388(10047), 871-880

Rubak, S., Sandbæk, A., Lauritzen, T., \& Christensen, B. (2005). Motivational interviewing: a systematic review and meta-analysis. British Journal General Practice, 55(513), 305-312

Schurer, S. (2017). Bouncing back from health shocks: Locus of control and labor supply. Journal of Economic Behavior \& Organization, 133, 1-20.

Snaith, R. P., Baugh, S. J., Clayden, A. D., Husain, A., \& Sipple, M. A. (1982). The clinical anxiety scale: an instrument derived from the Hamilton anxiety scale. The British Journal of Psychiatry, 141(5), 518-523.

Soto, C. J., \& John, O. P. (2017). The next Big Five Inventory (BFI-2): Developing and assessing a hierarchical model with 15 facets to enhance bandwidth, fidelity, and predictive power. Journal of Personality and Social Psychology, 113(1), 117

Tankamani, N., \& Jalali, M. (2018). A Comparative aggressiveness and assertiveness in coping styles students. International Journal of Applied Behavioral Sciences, 4(2), 8-12

Uliaszek, A. A., Hauner, K. K., Zinbarg, R. E., Craske, M. G., Mineka, S., Griffith, J. W., \& 
Rose, R. D. (2009). An examination of content overlap and disorder-specific predictions in the associations of neuroticism with anxiety and depression. Journal of Research in Personality, 43(5), 785-794

Verstraeten, K., Vasey, M. W., Raes, F., \& Bijttebier, P. (2009). Temperament and risk for depressive symptoms in adolescence: Mediation by rumination and moderation by effortful control. Journal of abnormal child psychology, 37(3), 349-361

Walton, K. E., Pantoja, G., \& McDermut, W. (2018). Associations Between Lower Order Facets of Personality and Dimensions of Mental Disorder. Journal of Psychopathology and Behavioral Assessment, 40(3), 465-475

Watson, D., \& Clark, L. A. (1999). The PANAS-X: Manual for the positive and negative affect schedule-expanded form

Watson, D., Kotov, R., \& Gamez, W. (2006). Basic dimensions of temperament in relation to personality and psychopathology. Personality and psychopathology, 7-38

Watson, D., Clark, L. A., Chmielewski, M., \& Kotov, R. (2013). The value of suppressor effects in explicating the construct validity of symptom measures. Psychological Assessment, 25(3), 929-941

Wilt, J. A., Bleidorn, W., \& Revelle, W. (2017). Velocity explains the links between personality states and affect. Journal of Research in Personality, 69, 86-95

Zinbarg, R. E., Uliaszek, A. A., \& Adler, J. M. (2008). The role of personality in psychotherapy for anxiety and depression. Journal of personality, 76(6), 1649-1688 
Supplementary tables

Supplementary table 1. Means and standard deviations of MADRS depression symptoms, CAS anxiety symptoms, and NEO-PI-R personality facets.

\begin{tabular}{|c|c|c|c|c|}
\hline & & Mean & $\begin{array}{l}\text { Standard } \\
\text { deviation }\end{array}$ & $\begin{array}{l}\text { Cronbach's } \\
\text { alpha }\end{array}$ \\
\hline \multirow[t]{2}{*}{ Affective disorder } & Depression symptoms & 5.98 & 8.59 & 0.91 \\
\hline & Anxiety symptoms & 2.72 & 4.03 & 0.88 \\
\hline \multirow[t]{6}{*}{ Neuroticism } & Anxiety & 17.30 & 6.45 & 0.88 \\
\hline & Angry hostility & 14.38 & 5.13 & 0.77 \\
\hline & Depression & 16.77 & 7.83 & 0.92 \\
\hline & \begin{tabular}{|l} 
Self-consciousness \\
\end{tabular} & 16.90 & 5.79 & 0.80 \\
\hline & Impulsivity & 17.11 & 4.72 & 0.69 \\
\hline & Vulnerability & 13.47 & 5.85 & 0.86 \\
\hline \multirow[t]{6}{*}{ Extroversion } & Warmth & 21.74 & 4.64 & 0.79 \\
\hline & Gregariousness & 17.28 & 5.81 & 0.82 \\
\hline & Assertiveness & 14.83 & 5.58 & 0.83 \\
\hline & Activity & 16.39 & 4.27 & 0.64 \\
\hline & Excitement-seeking & 16.45 & 5.41 & 0.72 \\
\hline & Positive emotion & 18.68 & 6.11 & 0.86 \\
\hline \multirow[t]{6}{*}{ Conscientiousness } & Competence & 19.79 & 4.46 & 0.74 \\
\hline & Order & 16.96 & 4.87 & 0.72 \\
\hline & Dutifulness & 21.24 & 4.28 & 0.65 \\
\hline & Achievement striving & 16.98 & 5.11 & 0.79 \\
\hline & Self-discipline & 17.75 & 5.58 & 0.83 \\
\hline & Deliberation & 17.31 & 4.85 & 0.77 \\
\hline \multirow[t]{6}{*}{ Agreeableness } & Trust & 18.76 & 5.24 & 0.84 \\
\hline & Straightforwardness & 20.36 & 4.71 & 0.73 \\
\hline & Altruism & 23.17 & 3.58 & 0.67 \\
\hline & Compliance & 18.20 & 4.46 & 0.67 \\
\hline & Modesty & 19.45 & 5.37 & 0.80 \\
\hline & Tendermindedness & 20.67 & 3.95 & 0.65 \\
\hline \multirow[t]{6}{*}{ Openness } & Fantasy & 18.79 & 5.10 & 0.77 \\
\hline & Aesthetics & 18.43 & 5.81 & 0.81 \\
\hline & Feelings & 21.81 & 3.95 & 0.68 \\
\hline & Actions & 17.43 & 3.99 & 0.64 \\
\hline & Ideas & 19.96 & 5.33 & 0.80 \\
\hline & Values & 22.43 & 3.36 & 0.58 \\
\hline
\end{tabular}


Supplementary table 2. Pearson's correlations between personality facets and affective disorders. All figures are given to 2 decimal places.

$*$ significant at $\mathrm{p}<0.05 . * *$ significant at $\mathrm{p}<0.01 . * * *$ significant at $\mathrm{p}<0.001$

\begin{tabular}{|c|c|c|c|}
\hline Personality trait & Personality facet & MADRS & CAS \\
\hline \multirow[t]{6}{*}{ Neuroticism } & Anxiety & $0.47 * * *$ & $0.53 * * *$ \\
\hline & Hostility & $0.34 * * *$ & $0.35 * * *$ \\
\hline & Depression & $0.63 * * *$ & $0.60 * * *$ \\
\hline & Self-consciousness & $0.46 * * *$ & $0.45 * * *$ \\
\hline & Impulsivity & 0.07 & 0.09 \\
\hline & Vulnerability & $0.52 * * *$ & $0.51 * * *$ \\
\hline \multirow[t]{6}{*}{ Extroversion } & Warmth & $-0.43 * * *$ & $-0.43 * * *$ \\
\hline & Gregariousness & $-0.41 * * *$ & $-0.42 * * *$ \\
\hline & Assertiveness & $-0.35 * * *$ & $-0.32 * * *$ \\
\hline & Activity & $-0.34 * * *$ & $-0.26 * * *$ \\
\hline & Excitement-seeking & $-0.27 * * *$ & $-0.29 * * *$ \\
\hline & Positive emotion & $-0.54 * * *$ & $-0.51 * * *$ \\
\hline \multirow[t]{6}{*}{ Conscientiousness } & Competence & $-0.41 * * *$ & $-0.41 * * *$ \\
\hline & Order & $-0.13^{*}$ & -0.03 \\
\hline & Dutifulness & $-0.22 * * *$ & $-0.17 * *$ \\
\hline & Achievement striving & $-0.25 * * *$ & $-0.17 * *$ \\
\hline & Self-discipline & $-0.27 * * *$ & $-0.23 * * *$ \\
\hline & Deliberation & -0.06 & -0.05 \\
\hline \multirow[t]{6}{*}{ Agreeableness } & Trust & $-0.37 * * *$ & $-0.37 * * *$ \\
\hline & Straightforwardness & $0.13 *$ & $0.13 *$ \\
\hline & Altruism & $-0.14 *$ & $-0.13^{*}$ \\
\hline & Compliance & -0.05 & -0.05 \\
\hline & Modesty & $0.32 * * *$ & $0.31 * * *$ \\
\hline & Tendermindedness & $0.13^{*}$ & 0.14 \\
\hline \multirow[t]{6}{*}{ Openness } & Fantasy & -0.05 & -0.06 \\
\hline & Aesthetics & 0.04 & 0.03 \\
\hline & Feelings & 0.002 & 0.00 \\
\hline & Actions & $-0.38 * * *$ & $-0.38 * * *$ \\
\hline & Ideas & -0.19 & $-0.22 * * *$ \\
\hline & Values & $-0.24 * * *$ & $-0.27 * * *$ \\
\hline
\end{tabular}


Supplementary tables 3 and 4. Correlations between NEO-PI-R facets. All figures are given to 2 decimal places.

$*$ significant at $\mathrm{p}<0.05$. ** significant at $\mathrm{p}<0.01$. *** significant at $\mathrm{p}<0.001$

\begin{tabular}{|c|c|c|c|c|c|c|c|c|c|c|c|c|c|c|c|}
\hline & 1 & 2 & 3 & 4 & 5 & 6 & 7 & 8 & 9 & 10 & 11 & 12 & 13 & 14 & 15 \\
\hline \multicolumn{16}{|l|}{1 Anxiety } \\
\hline 2 Hostility & $0.45^{* * *}$ & & & & & & & & & & & & & & \\
\hline 3 Depression & $0.8^{* * *}$ & $0.48^{* *}$ & & & & & & & & & & & & & \\
\hline 4 Self-consciousness & $0.64 * * * *$ & $0.43^{* * *}$ & $0.74^{* * *}$ & & & & & & & & & & & & \\
\hline 5 Impulsivity & $0.27^{* * *}$ & $0.3^{* * *}$ & $0.28^{* * *}$ & $0.25^{* * *}$ & & & & & & & & & & & \\
\hline 6 Vulnerability & $0.76^{* * *}$ & $0.48^{* * *}$ & $0.79 * * *$ & $0.7^{* * *}$ & $0.31^{* * *}$ & & & & & & & & & & \\
\hline 7 Warmth & $-0.31^{* * *}$ & $-0.36^{* * *}$ & $-0.41^{* * *}$ & $-0.41^{* * *}$ & 0.10 & $-0.38^{* * *}$ & & & & & & & & & \\
\hline 8 Gregariousness & $-0.26 * * *$ & \begin{tabular}{|l}
$-0.24^{* * *}$ \\
\end{tabular} & \begin{tabular}{|l}
$-0.37^{* * *}$ \\
\end{tabular} & \begin{tabular}{|l}
$-0.38^{* * *}$ \\
\end{tabular} & 0.03 & $-0.23^{* * *}$ & $0.71^{* * * *}$ & & & & & & & & \\
\hline 9 Assertiveness & $-0.50^{* * *}$ & $-0.16^{*}$ & $-0.57^{* * *}$ & \begin{tabular}{|l}
$-0.61^{* * *}$ \\
\end{tabular} & -0.09 & $-0.57^{* * *}$ & $0.39 * * *$ & $0.41^{* * *}$ & & & & & & & \\
\hline 10 Activity & $-0.34^{* * *}$ & $-0.13^{*}$ & $-0.45^{* * *}$ & $-0.40^{* * *}$ & -0.12 & $-0.47^{* * *}$ & $0.36^{* * *}$ & $0.32^{* * * * *}$ & $0.53^{* * *}$ & & & & & & \\
\hline 11 Excitement-seeking & $-0.23 * * *$ & 0.06 & $-0.22^{* * *}$ & $-0.26 * * *$ & $0.29 * * *$ & $-0.16^{*}$ & $0.38^{* * *}$ & $0.53^{* * *}$ & $0.39 * * *$ & $0.29 * * *$ & & & & & \\
\hline 12 Positive emotion & $-0.47^{* * *}$ & $-0.29 * * *$ & $-0.56^{* * *}$ & $-0.58^{* * *}$ & $0.16^{*}$ & $-0.51^{* * *}$ & $0.69 * * *$ & $0.55^{* * *}$ & $0.52^{* * *}$ & $0.44^{* * *}$ & $0.47^{* * *}$ & & & & \\
\hline 13 Competence & $-0.47^{* * *}$ & $-0.29 * * *$ & $-0.55^{* * *}$ & $-0.45^{* * *}$ & $-0.37^{* * *}$ & $-0.62^{* * *}$ & $0.23^{* * *}$ & 0.11 & $0.48^{* * *}$ & $0.38^{* * *}$ & -0.03 & $0.26^{* * *}$ & & & \\
\hline 14 Order & -0.09 & $\begin{array}{l}-0.04 \\
\end{array}$ & \begin{tabular}{|l|l|}
$-0.19 * *$ \\
\end{tabular} & $\begin{array}{l}-0.06 \\
\end{array}$ & $-0.20^{* *}$ & $-0.23^{* * *}$ & -0.05 & -0.08 & $0.15^{*}$ & $0.27^{* * *}$ & $-0.15^{*}$ & -0.01 & $0.36^{* * *}$ & & \\
\hline 15 Dutifulness & $-0.21^{* * *}$ & $-0.20^{* *}$ & $-0.28^{* * *}$ & $-0.15^{*}$ & $-0.38^{* * *}$ & $-0.36 * * *$ & 0.12 & -0.00 & $0.12^{*}$ & $0.36^{* * *}$ & $-0.13^{*}$ & 0.00 & $0.50^{* * *}$ & $0.45^{* * *}$ & \\
\hline 16 Achievement striving & $-0.28 * * *$ & -0.11 & $-0.39 * * *$ & $-0.29 * * *$ & $-0.28^{* * *}$ & $-0.47 * * *$ & $0.19 * *$ & 0.09 & $0.38^{* * *}$ & $0.56^{* * *}$ & 0.01 & $0.21^{* * *}$ & $0.57^{* * *}$ & $0.43 * * *$ & $0.53^{* * *}$ \\
\hline 17 Self-discipline & $-0.36 * * *$ & $-0.27^{* * *}$ & $-0.48^{* * *}$ & $-0.34 * * *$ & $-0.40^{* * *}$ & $-0.56 * * *$ & $0.14^{*}$ & 0.04 & $0.29 * * *$ & $0.46^{* * *}$ & -0.08 & 0.12 & $0.6 * * *$ & $0.51^{* * *}$ & $0.61^{* * *}$ \\
\hline 18 Deliberation & -0.12 & $-0.15^{*}$ & \begin{tabular}{|l|}
-0.11 \\
\end{tabular} & \begin{tabular}{|l|}
0.01 \\
\end{tabular} & $-0.47^{* * *}$ & $-0.19^{* *}$ & $-0.16^{*}$ & $-0.16^{* *}$ & -0.00 & -0.00 & $-0.36^{* * *}$ & $-0.22 * * *$ & $0.42^{* * *}$ & $0.42^{* * *}$ & $0.49 * * *$ \\
\hline 19 Trust & $-0.34^{* * *}$ & $-0.53^{* * *}$ & $-0.35^{* * *}$ & $-0.35^{* * *}$ & -0.03 & $-0.33^{* * *}$ & $0.59 * * *$ & $0.41^{* * *}$ & $0.22^{* * *}$ & $0.13^{*}$ & 0.10 & $0.51^{* * *}$ & $0.23^{* * *}$ & 0.02 & 0.10 \\
\hline 20 Straightforwardness & $0.18^{* *}$ & $-0.16^{* *}$ & $0.17^{* *}$ & $0.26^{* * *}$ & -0.07 & $0.15^{*}$ & 0.01 & -0.06 & $-0.31^{* * *}$ & -0.08 & $-0.34^{* * *}$ & $-0.25 * * *$ & -0.08 & 0.03 & $0.23^{* * *}$ \\
\hline 21 Altruism & -0.05 & $-0.35^{* * *}$ & $-0.13^{*}$ & -0.06 & -0.03 & $-0.15^{*}$ & $0.53^{* * *}$ & $0.30^{* * *}$ & 0.02 & $0.17^{* *}$ & 0.01 & $0.22^{* * *}$ & $0.24^{* * *}$ & 0.06 & $0.31^{* * *}$ \\
\hline 22 Compliance & 0.01 & $-0.52^{* * * *}$ & -0.01 & 0.08 & $-0.16^{* *}$ & -0.00 & $0.19^{* *}$ & 0.08 & $-0.29 * * *$ & -0.07 & $-0.27 * * *$ & -0.07 & -0.05 & -0.02 & $0.14^{*}$ \\
\hline 23 Modesty & $0.41^{* * *}$ & 0.02 & $0.49^{* * *}$ & $0.47^{* * *}$ & 0.09 & $0.45^{* * *}$ & $-0.21^{* * *}$ & $-0.25 * * *$ & $-0.52^{* * *}$ & $-0.35^{* * *}$ & $-0.35 * * *$ & $-0.43 * * *$ & $-0.35 * * *$ & -0.05 & -0.02 \\
\hline 24 Tendermindedness & $0.20^{* * *}$ & -0.12 & $0.25^{* * *}$ & $0.20^{* *}$ & $0.17^{* *}$ & $0.19 * *$ & $0.17^{* *}$ & -0.00 & $-0.28^{* * *}$ & -0.14 & $-0.17^{* *}$ & 0.02 & -0.11 & -0.09 & -0.00 \\
\hline 25 Fantasy & 0.06 & 0.08 & -0.01 & -0.08 & $0.27^{* * *}$ & 0.06 & $0.22^{* * *}$ & $0.17^{* *}$ & 0.11 & 0.01 & $0.28^{* * * *}$ & $0.31^{* * *}$ & -0.05 & $-0.18^{* *}$ & $-0.28^{* * *}$ \\
\hline 26 Aesthetics & 0.08 & -0.00 & 0.12 & -0.02 & $0.19^{* *}$ & 0.08 & $0.24^{* * *}$ & $0.14^{*}$ & 0.03 & 0.11 & $0.19^{* *}$ & $0.31^{* * *}$ & 0.00 & -0.00 & -0.06 \\
\hline 27 Feelings & $0.16^{*}$ & $0.13^{*}$ & $0.13^{*}$ & 0.02 & $0.36^{* * *}$ & 0.11 & $0.34^{* * *}$ & $0.21^{* * *}$ & 0.07 & $0.13^{*}$ & $0.20^{* *}$ & $0.35 * * *$ & -0.03 & 0.03 & -0.05 \\
\hline 28 Actions & $-0.31^{* * *}$ & \begin{tabular}{|c|c|c|c|} 
\\
\end{tabular} & 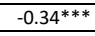 & 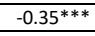 & 0.06 & $-0.29 * * *$ & $0.35 * * *$ & $0.39 * * *$ & $0.37^{* * *}$ & $0.29 * * *$ & $0.34^{* * *}$ & $0.47^{* * *}$ & $0.23 * * *$ & -0.10 & -0.04 \\
\hline 29 Ideas & $-0.19^{* *}$ & $-0.22^{* * *}$ & $-0.20^{* *}$ & $-0.28^{* * *}$ & -0.03 & $-0.22^{* * *}$ & $0.26^{* * *}$ & $0.15^{*}$ & $0.29 * * *$ & $0.27^{* * *}$ & $0.21^{* * *}$ & $0.36^{* * *}$ & $0.33^{* * *}$ & -0.01 & 0.08 \\
\hline 30 Values & $-0.18^{* *}$ & $-0.25^{* * *}$ & \begin{tabular}{|l|l}
$-0.18^{* *}$ \\
\end{tabular} & \begin{tabular}{|l|l}
$-0.19^{* *}$ \\
\end{tabular} & 0.11 & $-0.19^{* *}$ & $0.29 * * *$ & $0.17^{* *}$ & 0.08 & $0.13^{*}$ & $0.20^{* *}$ & $0.29 * * *$ & $0.21^{* * *}$ & -0.06 & 0.05 \\
\hline
\end{tabular}

\begin{tabular}{|c|c|c|c|c|c|c|c|c|c|c|c|c|c|c|}
\hline & 16 & 17 & 18 & 19 & 20 & 21 & 22 & 23 & 24 & 25 & 26 & 27 & 28 & 29 \\
\hline 17 Self-discipline & $0.69^{* * * *}$ & & & & & & & & & & & & & \\
\hline 18 Deliberation & $0.34^{* * *}$ & $0.41^{* * *}$ & & & & & & & & & & & & \\
\hline 19 Trust & 0.11 & 0.06 & 0.01 & & & & & & & & & & & \\
\hline 20 Straightforwardness & 0.02 & 0.08 & $0.15^{*}$ & $0.20^{* *}$ & & & & & & & & & & \\
\hline 21 Altruism & $0.16^{*}$ & $0.22 * * *$ & 0.08 & $0.41^{* * *}$ & $0.42^{* * *}$ & & & & & & & & & \\
\hline 22 Compliance & -0.10 & 0.01 & $0.21^{* * *}$ & $0.39^{* * *}$ & $0.42^{* * *}$ & 0.38 & & & & & & & & \\
\hline 23 Modesty & $-0.22^{* * *}$ & $-0.15^{*}$ & 0.05 & $-0.08^{* * *}$ & $0.55^{* * *}$ & $0.20^{* *}$ & $0.40^{* * *}$ & & & & & & & \\
\hline 24 Tendermindedness & -0.06 & -0.06 & -0.04 & $0.24^{* * *}$ & $0.40^{* * *}$ & $0.44^{* * *}$ & $0.33^{* * *}$ & $0.38^{* * * *}$ & & & & & & \\
\hline 25 Fantasy & $-0.18^{* *}$ & $-0.23 * * *$ & $-0.23^{* * *}$ & 0.06 & $-0.23^{* * *}$ & 0.01 & $-0.12^{*}$ & $-0.19^{* * *}$ & 0.05 & & & & & \\
\hline 26 Aesthetics & 0.07 & -0.08 & -0.12 & $0.19^{* *}$ & -0.11 & 0.13 & -0.07 & -0.06 & $0.29 * * *$ & $0.36^{* * *}$ & & & & \\
\hline 27 Feelings & 0.03 & -0.07 & $-0.17^{* *}$ & $0.14^{*}$ & -0.04 & $0.24^{* * *}$ & -0.04 & -0.01 & $0.33^{* * *}$ & $0.41^{* * *}$ & $0.53^{* * * *}$ & & & \\
\hline 28 Actions & $0.13^{*}$ & 0.11 & $-0.19^{* *}$ & $0.31^{* * *}$ & -0.11 & 0.07 & -0.10 & $-0.25^{* * *}$ & -0.01 & $0.17^{* *}$ & $0.19 * *$ & $0.16^{*}$ & & \\
\hline 29 Ideas & $0.23^{* * *}$ & 0.11 & -0.02 & $0.17^{* *}$ & -0.17 & 0.07 & -0.07 & $-0.27^{* * *}$ & 0.03 & $0.35^{* * *}$ & $0.48^{* * *}$ & $0.24^{* * *}$ & $0.38 * * *$ & \\
\hline 30 Values & 0.04 & 0.11 & -0.06 & $0.24^{* * *}$ & 0.03 & $0.22^{* * *}$ & $0.13^{*}$ & 0.04 & $0.27^{* * *}$ & $0.23^{* * *}$ & $0.16^{*}$ & $0.25 * * *$ & $0.37 * * *$ & $0.37^{* * *}$ \\
\hline
\end{tabular}




\section{Analysis script}

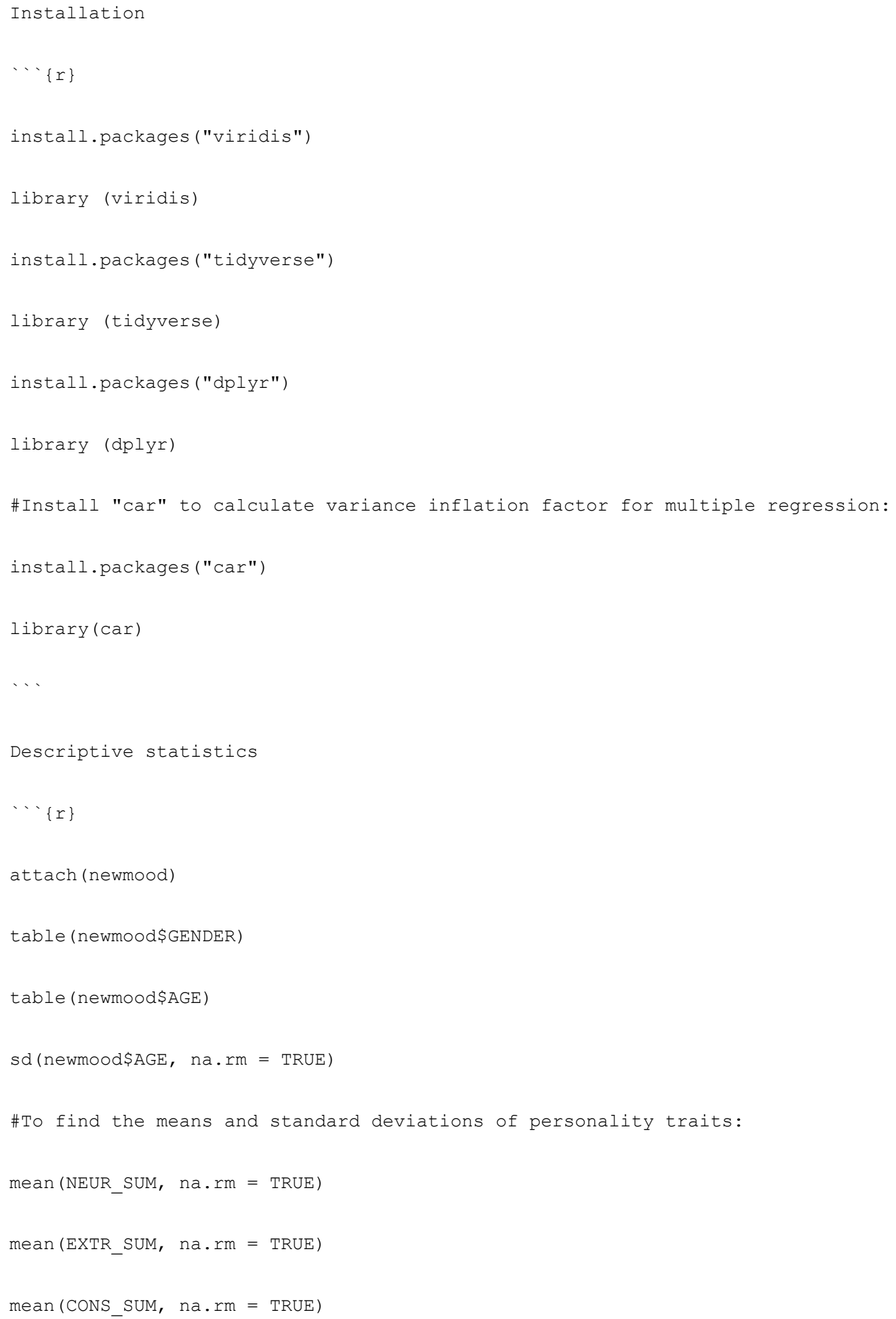




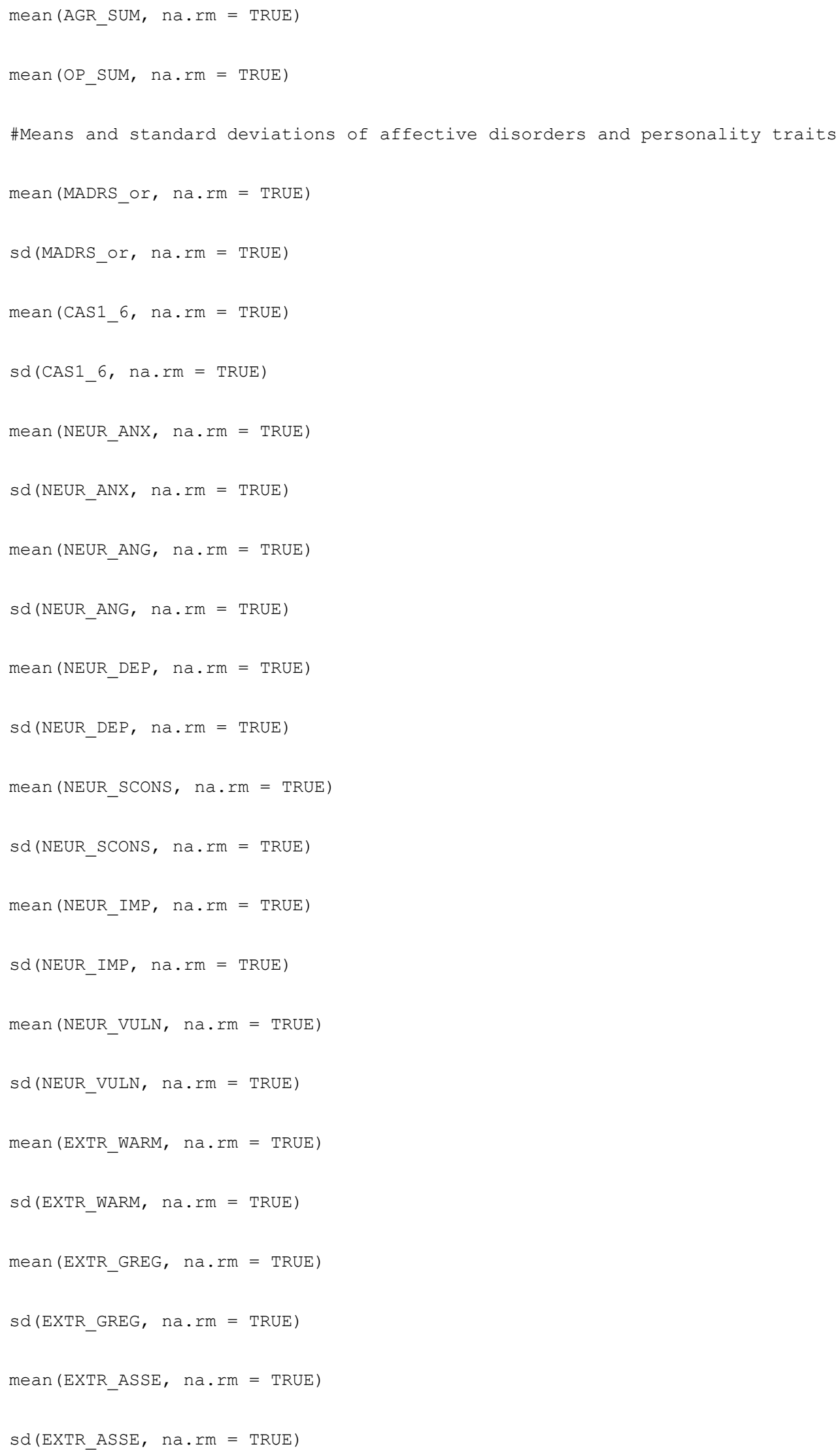




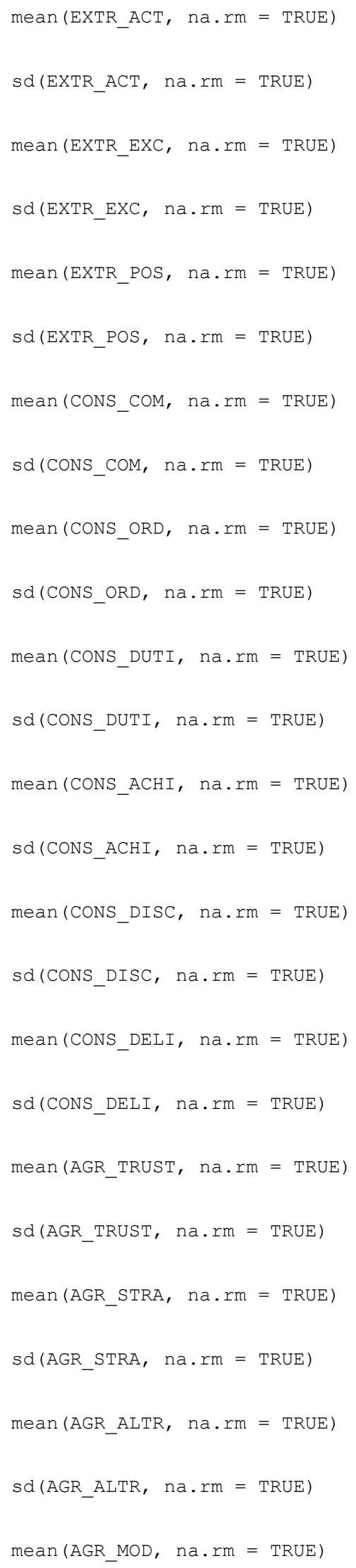




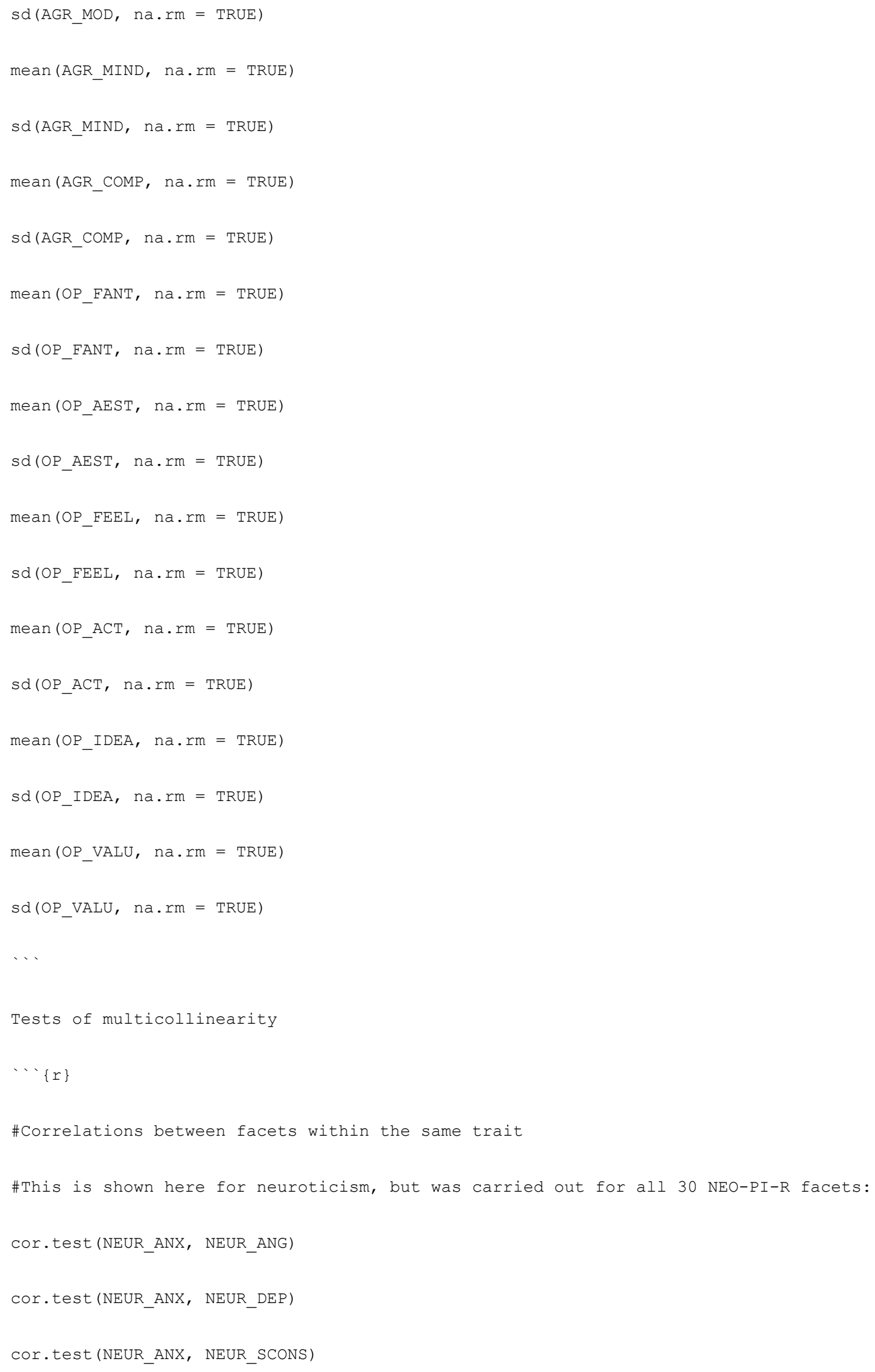




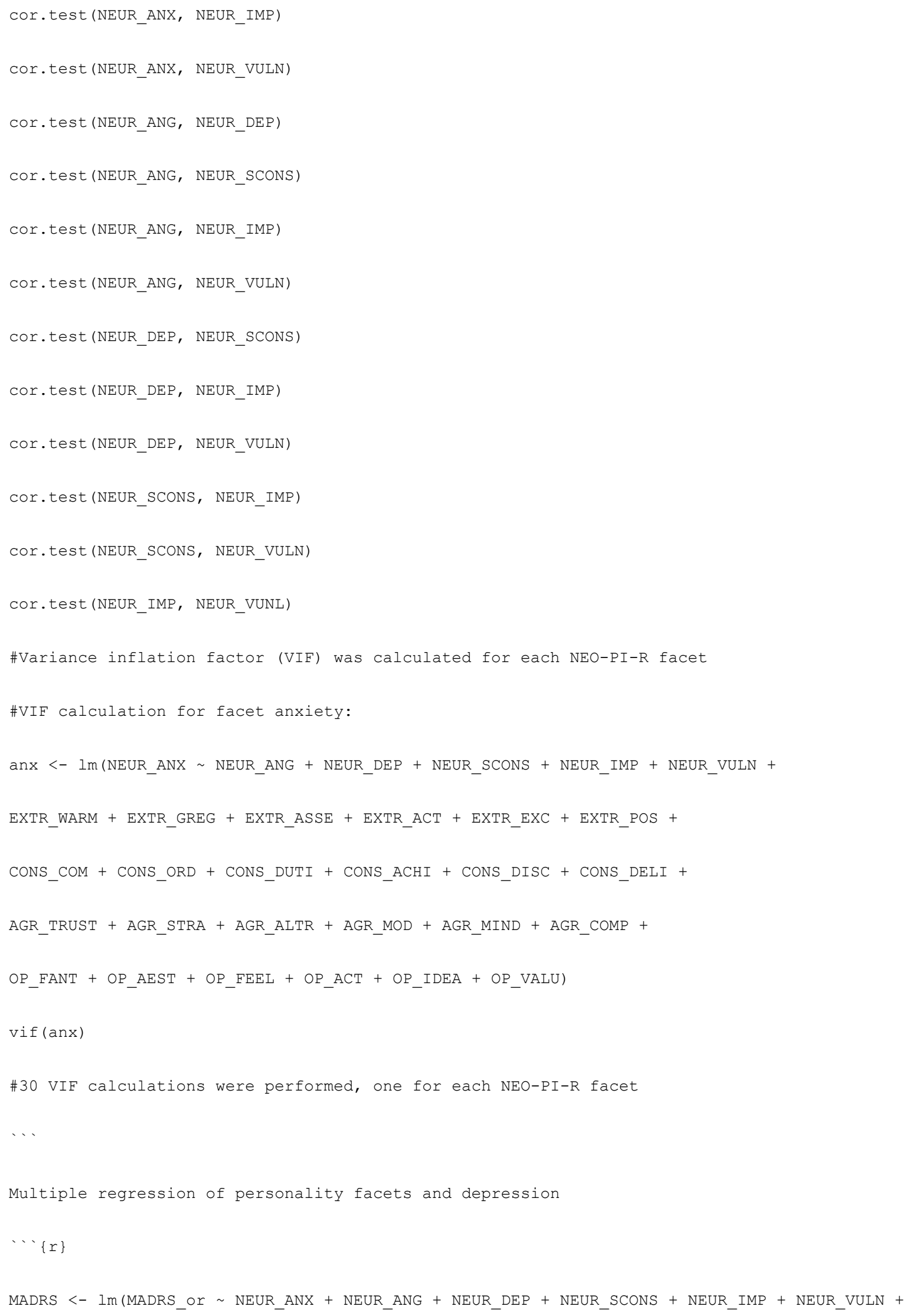




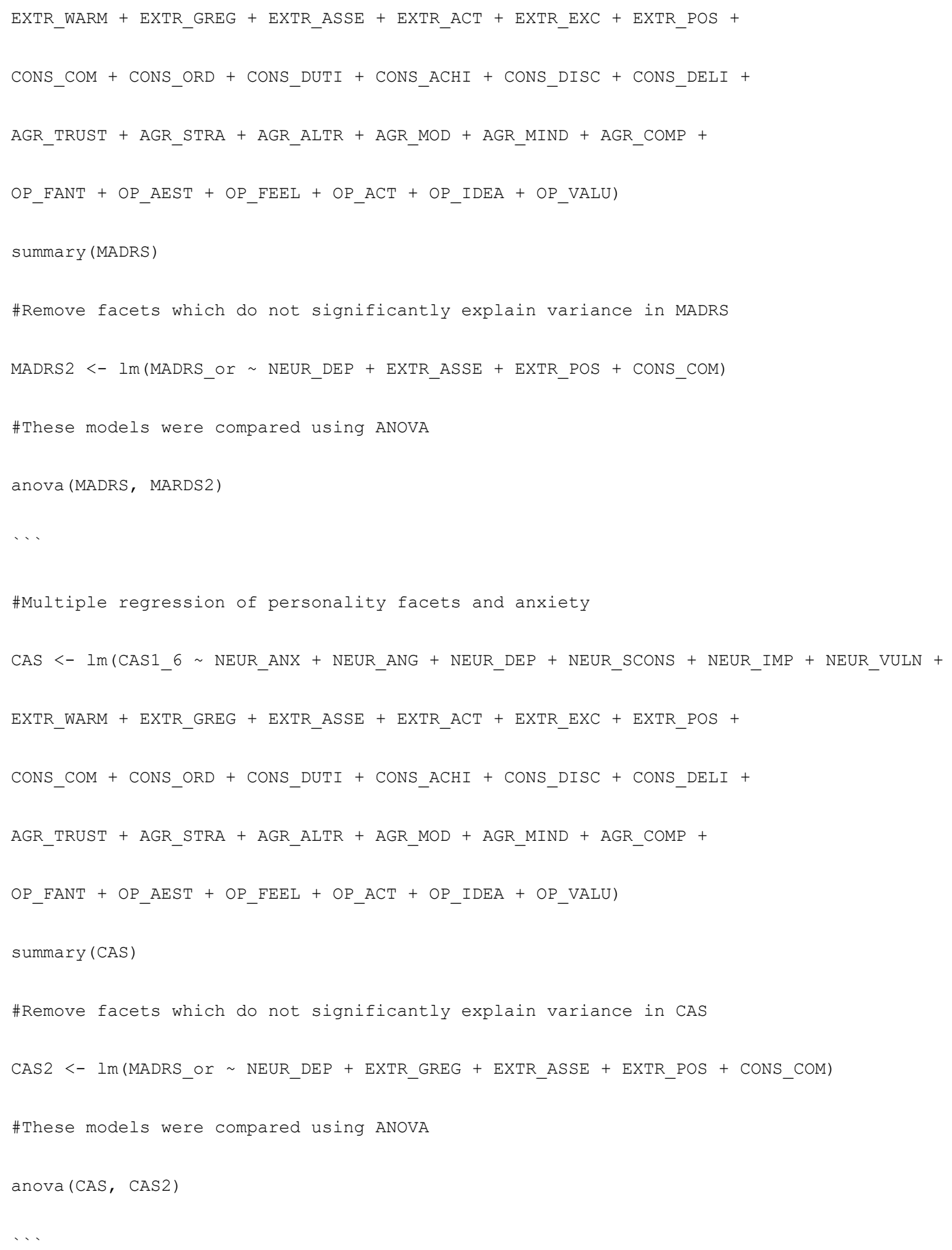

